\title{
The Management of Urban Solid Waste in Sustainable Development in A Peruvian Municipality In The Context of The Coronavirus Pandemic (Covid-19)
}

\author{
Anwar Julio Yarin Achachagua ${ }^{a}$, Abad Antonio Surichaqui Mateo ${ }^{b}$, Anibal Sucari Leónc, Wilber \\ Pastor Contreras $^{d}$, Guido Benedicto Palumbo Pinto ${ }^{e}$, Miguel Ángel Castillo Corzo
}

a, National Major University of San Marcos, Perú, Faculty of Industrial Engineering.

${ }^{\mathrm{b}}$ National University of Huancavelica, Perú

c,d National University of Altiplano, Perú

e Private University of Tacna, Perú

f National Major University of San Marcos, Perú, Faculty of Physical Sciences

Article History: Received: 10 November 2020; Revised 12 January 2021 Accepted: 27 January 2021; Published online: 5 April 2021

\begin{abstract}
The purpose of this research article was to determine the relationship between Solid Waste Management and Sustainable Development in a municipality of Lima, Peru in the context of COVID-19. The methodology was quantitative approach, correlational level, cross-sectional and non-experimental design. The population was made up of a total of 274 workers, while through probability sampling a total of 161 workers were obtained. It was used as the survey technique for each study variable, obtaining a reliability of 0.918 for the Solid Waste Management instrument and of 0.663 for Sustainable Development. To measure the correlation between the variables, the Spearman Rho Coefficient was used using the Statistical Package of Social Sciences (SPSS) version 24. Among the results, it was obtained that the Spearman Rho correlation coefficient is weak and significant $(\mathrm{r}=0.469, \mathrm{p}=0.000)$, while for the solid waste management dimension a moderate and significant correlation was obtained $(\mathrm{r}=0.626, \mathrm{p}=0.000)$; finally, for the solid waste management dimension, a weak correlation was obtained and without significance $(r=0.135, p=0.088)$. In conclusion, a better level of solid waste management will be reflected in a better level of sustainable development in the municipality under study.
\end{abstract}

Keywords: solid waste management, sustainable development, urban solid waste, COVID-19

\section{Introduction}

The generation of solid waste is a natural consequence of life; in this way, the elimination of these wastes is consistent with the improvement of the quality of life. Initially, solid waste management (SRM) techniques aimed to remove waste from those habitable areas as a means of maintaining public health. Then, with awareness of the dangers of uncontrolled disposal, measures were designed and implemented mainly through landfills. Currently, materials and energy recovery technologies have been devised, coupled with modern global systems (Shekdar, 2009).

The consequence is environmental degradation caused by improper waste disposal. The impact of disposed wastes is composed of the following: contamination of the surface and groundwater through leachate; soil contamination by direct contact with wastes or leachates; air pollution from burning waste; spread of diseases by different vectors such as birds, insects and rodents and uncontrollable release of methane by anaerobic decomposition of waste (Nguyen \& Schnitzer, 2009).

In this context, the management of urban solid waste is considered an important concern for public health, the economy and the environment, especially in developing countries (Ferronato et al., 2018). As indicated (Ikhlayel\& Nguyen, 2017) that the management of urban solid waste is one of the most important and complex by-products of humanity; its importance lies in the fact that it is a day-to-day topic that we deal with. The significant amount of municipal solid waste generated makes it a complex health, environmental, social and economic problem. All this endangers public health, including residents and workers, due to inappropriate management practices; this happens mainly in developing countries

Peruvian society has experienced vast urban growth in recent decades. In addition to the centralization that has caused social, economic and environmental changes; For this reason, it has been difficult to organize a suitable infrastructure for the population that lives in urban conditions for short periods of time. Thus, solid waste management is one of the fundamental concerns of society, since it also represents the level of urban development (López, 2007). 
Due to the aforementioned, it is convenient to know how closely related the Solid Waste Management and Sustainable Development variables are; in such a way that the municipality under study can carry out a better management in this regard, for which the following objectives were proposed:

a. Determine the relationship between Urban Solid Waste Management in Sustainable Development in a Peruvian Municipality in the context of COVID-19.

b. Determine the relationship between solid waste management in sustainable development in a Peruvian Municipality in the context of COVID-19.

c. Determine the relationship between solid waste management in sustainable development in a Peruvian Municipality in the context of COVID-19.

\section{Materials and methods}

The research was of a quantitative approach and of an applied type, because the variables are measured and it focuses on applying knowledge to contribute to the resolution of a specific problem. According to Hernández, Fernández and Baptista (2014) in the quantitative approach, the collection of information is used to contrast the hypotheses, in such a way that it allows establishing guidelines and verifying theories; Likewise, applied research allows the application of knowledge to solve a practical problem.

The population consisted of a total of 274 workers from the municipality of the town of Lima, Peru. The sampling was probabilistic and was calculated using the following formula:

$$
n=\frac{N x Z^{2} x p x q}{d^{2} x N-1+Z^{2} x p x q}
$$

Where:

$$
\begin{aligned}
& \mathrm{N}: \text { Population } \\
& \mathrm{Z}=1.96 \text { at } 95 \% \text { confidence } \\
& \mathrm{p}=0.5 \\
& \mathrm{q}=0.5 \\
& \mathrm{~d}=5 \% \text { error }
\end{aligned}
$$

Therefore, the following is obtained:

$$
n=\frac{274 \times 1.96^{2} \times 0.5 \times 0.5}{0.05^{2} 274^{-1}+1.96^{2} \times 0.5 \times 0.5}=161 \text { workers }
$$

Once the number of workers to be surveyed had been found, the technique used for both variables was the survey; Thus, for the Solid Waste Management variable, the reference was made to (Valdera, 2020), who operationalized the variable in the solid waste management dimension, including for this a solid waste management plan, characterization, segregation and formalization of recyclers; while for the solid waste management dimension, items on the sanitary landfill, solid waste collection, treatment and management of hazardous waste were included. From this instrument a high reliability was obtained with a value of 0.918 . On the other hand, for the sustainable development variable, (Olsson, 2017) was taken into account, who took into consideration 50 items divided into 3 parts: the first part was on economic development, resource consumption, species conservation, human rights, education and infectious diseases; the second part was on the use of natural resources, laws and regulations, society and access to equality at work. In the third part, items on recycling, environmental awareness, respect and support were included. It is important to mention that for the second instrument, the reliability was calculated by the researchers, where a value of 0.663 was obtained, which refers to a high average reliability due to its proximity to the unit. Likewise, for both instruments the content validation was obtained through 5 experts in the field, thus obtaining a very high validation and the value of the Aiken V coefficient of 1 . 


\section{Results}

Table 1. Descriptive statistics of the study variables

\begin{tabular}{|c|c|c|c|c|c|}
\hline & & $\begin{array}{l}\text { Solid } \\
\text { wastemanagement }\end{array}$ & $\begin{array}{l}\text { Solid } \\
\text { wasteadministration }\end{array}$ & $\begin{array}{l}\text { Solid } \\
\text { wastehandling }\end{array}$ & Sustainabledevelopment \\
\hline $\mathrm{N}$ & $\begin{array}{l}\mathrm{V} \\
\text { alid }\end{array}$ & 161 & 161 & 161 & 161 \\
\hline Mean & & 1.69 & 2.04 & 1.70 & 1.98 \\
\hline Standard err & r of the mean & 0.049 & 0.068 & 0.044 & 0.043 \\
\hline Median & & 2.00 & 2.00 & 2.00 & 2.00 \\
\hline Mode & & 2 & 3 & 2 & 2 \\
\hline Standard de & iation & 0.625 & 0.861 & 0.557 & 0.547 \\
\hline Variance & & 0.390 & 0.742 & 0.311 & 0.299 \\
\hline Asymmetry & & 0.338 & -0.084 & 0.026 & -0.017 \\
\hline $\begin{array}{l}\text { Standard } \\
\text { skewness }\end{array}$ & error of & 0.191 & 0.191 & 0.191 & 0.191 \\
\hline Kurtosis & & -0.651 & -1.652 & -0.563 & 0.402 \\
\hline Kurtosis sta & dard error & 0.380 & 0.380 & 0.380 & 0.380 \\
\hline Percentiles & $5^{2}$ & 1.00 & 1.00 & 1.00 & 2.00 \\
\hline & $0^{5}$ & 2.00 & 2.00 & 2.00 & 2.00 \\
\hline & $5^{7}$ & 2.00 & 3.00 & 2.00 & 2.00 \\
\hline
\end{tabular}

Source: SPSS v. 24

From table 1, it can be seen that with $95 \%$ confidence for the variable a higher average in the solid waste management dimension with 2.04 points, while a lower average in the solid waste management variable with 1.69 points; a median is 2 points, which represents $50 \%$ of the data for both the variables and their dimensions. There is also a higher standard deviation in the solid waste management dimension with 0.86 points and a lower standard deviation in the Sustainable Development variable with 0.547 points, which refer to variations with respect to the mean. Likewise, there is a higher asymmetry in the Solid Waste Management variable with 0.338 points that represents a positive curve and meets to the left of the mean; In its counterpart, there is a lower asymmetry in the Solid Waste Management dimension with -0.084, which represents a negative curve and meets to the right of the mean.In addition, there is a higher kurtosis in the Sustainable Development variable with a value 0.402 that refers to a curve longer than normal because it is greater than 0 and is known as leptokurtic; in contrast to the solid waste management dimension with a kurtosis of -1.652 , which refers to a more flattened than normal as it is less than 0 and is called platicurtic. Finally, in the 25th percentile there is a higher value of 2 points in the Sustainable development variable, which refers to the fact that $75 \%$ of the workers surveyed responded on the Likert scale with responses between 3-5 (sometimes, almost always and always) in said variable. At the 50th percentile, the same value of 2 points was found for both the variables and dimensions, which refers to the fact that $50 \%$ of the workers responded on the Likert scale with responses between 3-5 and a higher value was obtained at the 75th percentile. in the solid waste management dimension with 3 points, which indicates that $25 \%$ responded in this dimension with values between 4 and 5 on the Likert scale. 
Table 2. Levels of Solid Waste Management and Sustainable Development

\begin{tabular}{|c|c|c|c|c|c|c|c|c|c|}
\hline & & & \multicolumn{7}{|c|}{ Sustainabledevelopment } \\
\hline & & & Low & $\%$ & Medium & $\%$ & High & $\%$ & Total \\
\hline \multirow[t]{6}{*}{ Solid wastemanagement } & Low & Recount & 22 & $84.60 \%$ & 42 & $37.2 \%$ & 0 & $0.0 \%$ & 64 \\
\hline & & $\%$ of total & $13.7 \%$ & & $26.1 \%$ & & $0.0 \%$ & & $39.8 \%$ \\
\hline & Medium & Recount & 4 & $15.40 \%$ & 61 & $54.0 \%$ & 18 & $81.8 \%$ & 83 \\
\hline & & $\%$ of total & $2.5 \%$ & & $37.9 \%$ & & $11.2 \%$ & & $51.6 \%$ \\
\hline & High & Recount & 0 & $0.00 \%$ & 10 & $8.8 \%$ & 4 & $18.2 \%$ & 14 \\
\hline & & $\%$ of total & $0.0 \%$ & & $6.2 \%$ & & $2.5 \%$ & & $8.7 \%$ \\
\hline \multirow[t]{2}{*}{ Total } & & Recount & 26 & $100.00 \%$ & 113 & $100.0 \%$ & 22 & $100.0 \%$ & 161 \\
\hline & & $\%$ of total & $16.1 \%$ & & $70.2 \%$ & & $13.7 \%$ & & $100.0 \%$ \\
\hline
\end{tabular}

\section{Source: SPSS v. 24}

Table 2 shows both the frequencies and percentages of the study variables, there is a higher percentage in the low level of Solid Waste Management with 26.1\%, that is, 42 workers detected a medium level of sustainable development; Similarly, 37.9\% (61) of the workers who perceived a medium level of solid waste management, also detected a medium level of sustainable development. Likewise, 6.2\% (10) of the workers who detected a high level of solid waste management, also perceived a medium level of sustainable development in a municipality located in Lima, Peru.

Table 3. Correlation between the study variables

\begin{tabular}{|c|c|c|c|}
\hline & & & $\begin{array}{l}\text { Sustainabledevelop } \\
\text { ment }\end{array}$ \\
\hline \multirow[t]{9}{*}{ Spearman Rho } & $\begin{array}{c}\text { Solid } \\
\text { wastemanagement }\end{array}$ & $\begin{array}{l}\text { Correlationcoeffic } \\
\text { ient }\end{array}$ &, $469^{* * *}$ \\
\hline & & Sig. & 0.000 \\
\hline & & $\mathrm{N}$ & 161 \\
\hline & $\begin{array}{l}\text { Solid } \\
\text { wasteadministration }\end{array}$ & $\begin{array}{l}\text { Correlationcoeffic } \\
\text { ient }\end{array}$ &, $626^{* *}$ \\
\hline & & Sig. & 0.000 \\
\hline & & $\mathrm{N}$ & 161 \\
\hline & $\begin{array}{c}\text { Solid } \\
\text { wastehandling }\end{array}$ & $\begin{array}{l}\text { Correlationcoeffic } \\
\text { ient }\end{array}$ & , 135 \\
\hline & & Sig. & 0.088 \\
\hline & & $\mathrm{N}$ & 161 \\
\hline
\end{tabular}

Source: SPSS v. 24

From table 3, it can be seen that Spearman's Rho correlation coefficient is weak and significant $(\mathrm{r}=0.469, \mathrm{p}=$ $0.000)$, while for the solid waste management dimension a moderate and significant correlation was obtained ( $\mathrm{r}=$ $0.626, p=0.000$ ); Finally, for the solid waste management dimension, a weak correlation was obtained and without significance $(0.135, \mathrm{p}=0.088)$. It is important to mention that according to (Martínez, Tuya, Martínez, Pérez, \&Cánovas, 2009) the Spearman Rho correlation values between 0.51-0.75 are considered moderate, while values between $0.26-0.49$ are considered weak and between $0.00-0.25$ are considered scarce. 


\section{Discussion}

The general objective was to determine the relationship between solid waste management and sustainable development, from which an $r=0.469$ and $p=0.000$ was obtained, which refers to a weak and significant correlation.

The specific objective 1 was to determine the relationship between solid waste management and sustainable development, whose value was $r=0.626$ and $p=0.000$, which represents a moderate and significant correlation.

The specific objective 2 was to determine the relationship between solid waste management and sustainable development, whose value was $r=0.135$ and $p=0.088$, which reflects a scarce correlation and no significance.

The results obtained coincide with (Gilardino, Rojas, Mattos, Larrea, \& Vásquez, 2017) who, through the use of operational research, managed to reduce the number of collection sites by installing and using the available container capacity, at the same time that the maximum walking distance for citizens in the Comas district was met without mixing recyclable and general waste. In addition, with (Ianoş, and others, 2012), who inquired about the low participation in the collection of solid waste, thus obtaining a direct correlation between low motivation, the fact that participation is not mandatory and inappropriate ecological behavior.

Likewise, it is pertinent to mention (Troschinetz\&Mihelcic, 2009), who obtained the factors that influence the sustainable recycling of solid waste management in developing countries, which are the following: government policy, public finances, waste characterization, I collect and waste segregation, home education, home-economy, solid waste management, environmental education of workers, solid waste management plan, technological and human resources and availability of land.

According to (Adeniran, Nubi, \&Adelopo, 2017) The organic waste generated could be managed through the formation of compounds or integration with the wastewater management system. Likewise, strategic policy and community participation is necessary for source reduction and waste recycling improvement. The characterization of waste provided a better understanding of the generation of waste on the University campus and how it should incentivize it based on a better decision on the sustainable strategy in waste management on campus.

\section{Conclusions}

- The development of the research allowed to know in greater depth about solid waste management and sustainable development through the bibliographic review, as well as the relationship between the study variables.

- The research results provide transcendental information for a municipality located in Lima, Peru regarding solid waste management and sustainable development, which can serve as a basis for future research.

- The correlation between the study variables was weak and significant with $r=0.469$ and $p=0.000$, which means that the changes made to a greater or lesser extent in the management of solid waste will be weakly reflected in the level of sustainable development perceived by workers.

- The correlation between solid waste management and sustainable development was moderate and significant with $r=0.626$ and $p=0.000$, which means that changes made to a greater or lesser extent in solid waste management are they will be moderately reflected in the level of sustainable development perceived by workers.

- The correlation between solid waste management and sustainable development was scarce and without significance with $r=0.135$ and $p=0.088$, which means that the changes made to a greater or lesser extent in the management of solid waste, they will be poorly reflected in the level of sustainable development perceived by workers.

\section{Acknowledgement}

We are grateful to the sample of workers who filled out the surveys, as well as to the university that allowed the research to be carried out at their institution.

\section{References}

Adeniran, A. E., Nubi, A. T., \& Adelopo, A. O. (2017). Solid waste generation and characterization in the University of Lagos for a sustainable waste management. Waste Management(67), 3-10. doi:10.1016/j.wasman.2017.05.002

Ferronato, N., Gorritty Portillo, M. A., Guisbert Lizarazu, E. G., Torretta, V., Bezzi, M., \& Ragazzi, M. (2018). The municipal solid waste management of La Paz (Bolivia): Challenges and opportunities for a sustainable development. Waste Management \& Research, 36(3), 288-299. doi:10.1177/0734242X18755893

Gilardino, A., Rojas, J., Mattos, H., Larrea, G., \& Vásquez, I. (2017). Combining operational research and Life Cycle Assessment to optimize municipal solid waste collection in a district in Lima (Peru). Journal of Cleaner Production(156), 589-603. doi:10.1016/j.jclepro.2017.04.005 
Hernández, R., Fernández, C., \& Baptista, P. (2014). Investigation Methodology. México D.F.: McGraw Hill. Ianoş, I., Zamfir, D., Stoica, V., Cercleux, L., Schvab, A., \& Pascariu, G. (2012). Municipal solid waste management for sustainable development of Bucharest metropolitan area. Environmental Engineering and Management Journal, 11(2), 359-369. Retrieved from: https://www.researchgate.net/profile/Daniela_Zamfir/publication/260664771_134_IANOS_Ioan_ZAMFIR_ D_STOICA_VI_CERCLEUX_LA_SCHVAB_A_PASCARIU_G_2012_Municipal_solid_waste_manageme nt_for_sustainable_development_of_Metropolitan_Bucharest_Area_Engineering_and_En

Ikhlayel, M., \& Nguyen, L. H. (2017). Integrated Approaches to Water Resource and Solid Waste Management for Sustainable Development. Sustainable Development, 25(6), 467-481. doi:10.1002/sd.1683

López, A. (2007). Solid waste management and development: a case study in Lima, Peru.(Thesis Degree). Tampere Polytechnic. Finland.

Martínez, R. M., Tuya, L. C., Martínez, M., Pérez, A., \& Cánovas, A. M. (2009). The correlation coefficient of the Spearman ranks characterization. Habanera Journal of Medical Sciences, 8 (2), 1-19. Retrieved from http://scielo.sld.cu/pdf/rhcm/v8n2/rhcm17209.pdf

Nguyen, U., \& Schnitzer, H. (2009). Sustainable solutions for solid waste management in Southeast Asian countries. Waste Management, 29(6), 1982-1995. doi:10.1016/j.wasman.2008.08.031

Olsson, D. (2017). Center of Science, Mathematics and Engineering Education Research. Questionnaire on Sustainable Development - $\quad$ Year 6. Recuperado de: http://kau.divaportal.org/smash/get/diva2:1080964/DATASET01.pdf

Shekdar, A. (2009). Sustainable solid waste management: An integrated approach for Asian countries. Waste Management, 29(4), 1438-1448. doi:10.1016/j.wasman.2008.08.025

Troschinetz, A. M., \& Mihelcic, J. R. (2009). Sustainable recycling of municipal solid waste in developing countries. Waste Management, 29(2), 915-923. doi:10.1016/j.wasman.2008.04.016

Valdera, M. (2020). Management and management of solid waste in the municipalities of Pacasmayo and Guadalupe, La Libertad, 2019. (Master's Thesis). César Vallejo University, Peru.Retrieved from:https://repositorio.ucv.edu.pe/bitstream/handle/20.500.12692/40658/VALDERA_SMA.pdf?sequence=1 \&isAllowed $=\mathrm{y}$. 